\title{
Eficiência nutricional da soja RR na ausência do glifosato
}

\section{Nutritional efficiency of glyphosate-resistant soybean without glyphosate}

\author{
Janine Mesquita GONÇALVES ${ }^{1}$; Eli Regina Barboza de SOUZA ${ }^{2}$; Eliana Paula FERNANDES ${ }^{3}$; \\ Wilson Mozena LEANDRO ${ }^{4}$; Cássio Jardim TAVARES ${ }^{5}$ \\ ${ }^{1}$ Autor para correspondência. Engenheira Agrônoma do Instituto Federal Goiano - Câmpus Urutaí e \\ Mestre em Agronomia pela Universidade Federal de Goiás. Os dados a serem publicados são parte \\ da dissertação "Acúmulo de nutrientes em soja transgênica no Cerrado Goiano". \\ janine_mesquita@yahoo.com.br \\ ${ }^{2}$ Professor Adjunto da Escola de Agronomia e Engenharia de Alimentos da Universidade Federal de \\ Goiás. eliregina1@gmail.com \\ ${ }^{3}$ Professor Adjunto da Escola de Agronomia e Engenharia de Alimentos da Universidade Federal de \\ Goiás. elianafernandesufg@gmail.com \\ ${ }^{4}$ Professor Adjunto da Escola de Agronomia e Engenharia de Alimentos da Universidade Federal de \\ Goiás.wilsonufg@gmail.com \\ ${ }^{5}$ Discente em Agronomia do Instituto Federal Goiano - Câmpus Urutaí. \\ cassiojardimtavares@hotmail.com
}

Recebido em: 13-01-2013; Aceito em: 29-09-2013

\section{Resumo}

O acúmulo de nutrientes pode ser influenciado por vários fatores, entre eles os quais a aplicação de produtos químicos. Com o advento da transgenia, observa-se a crescente utilização do glifosato por diversos fatores, porém quando utilizado o herbicida pode provocar redução na fitomassa, acúmulo de nutrientes e produtividade. $O$ presente estudo objetivou avaliar o desempenho de cultivares convencionais e transgênicas de soja, sem aplicação de glifosato, quanto à produção de massa seca, acúmulo de nutrientes e produtividade. Para tanto, foram plantadas cinco cultivares convencionais e seis transgênicas, com coleta da parte aérea aos 20; 40; 60; 80 e 100 dias após o plantio (DAP), para a determinação da fitomassa e o acúmulo dos nutrientes (N, P, K, Ca, Mg, S, Cu, Fe, Mn e Zn). Ao final do ciclo, coletaram-se os grãos e determinou-se a produtividade. O delineamento experimental foi o em parcelas subdivididas no tempo, com quatro repetições. Comparando-se as similares genéticas, observa-se que a produtividade nas cultivares transgênicas é maior que nas convencionais. Concluiu-se que a soja convencional e a transgênica apresentam a mesma eficiência nutricional quanto à produção de fitomassa, acúmulo de nutrientes e produtividade.

Palavras-chave adicionais: absorção de nutrientes; Glycine Max; produção.

\begin{abstract}
The nutrient accumulation can be influenced by several factors, among them the application of chemical products. With the development of glyphosate-resistant cultivars it has been observed an increase using of glyphosate due to several factors, however the herbicide can induce reduction of biomass, nutrient accumulation and productivity. The objective of this study was evaluate the performance of conventional and transgenic soybean cultivars without glyphosate application, on dry matter production, nutrient accumulation and productivity. Therefore, five conventional cultivars and six transgenic were grown without glyphosate application. The sampling was carried out at 20, 40,60, 80 and 100 days after planting (DAP) to determine the biomass and nutrient accumulation (N, P, K, $\mathrm{Ca}, \mathrm{Mg}, \mathrm{S}, \mathrm{Cu}, \mathrm{Fe}, \mathrm{Mn}$ and $\mathrm{Zn}$ ). At the end of the experiment the productivity was determined by harvesting the grains. The experimental design was a split plot with four repetitions. Comparing the genetic similarity the transgenic cultivars presented higher yields compared to conventional. Concluding, the conventional and transgenic soybean presented the same nutritional efficiency for biomass production, nutrient accumulation and productivity.
\end{abstract}

Additional keywords: Glycine max; nutrient uptake; production. 


\section{Introdução}

A soja é a cultura de maior expressão no Brasil. Na safra de 2012/2013, o Brasil foi responsável por uma produção de $81.456,70$ milhões de toneladas de soja, em 27,72 milhões de ha. A região Centro-Sul foi responsável por grande parte da produção, totalizando $73.520,00$ mil toneladas de soja em $24.412,80$ mil ha (CONAB, 2013). Para obtenção destes índices, observa-se a necessidade da utilização de novas tecnologias, como a transgenia, porém a utilização irracional pode provocar impactos ainda pouco divulgados (GUIVANT, 2006).

O glifosato é um herbicida de amplo espectro que vem sendo utilizado na produção de soja ao longo de todo o ciclo da cultura. Este influencia diretamente na fisiologia do vegetal, mesmo nas cultivares transgênicas. A aquisição de nutrientes do solo, seu acúmulo e a produção de matéria seca são influenciados diretamente pela utilização do herbicida (CAVALIERI et al., 2012).

A frequência de aplicação do glifosato pode induzir deficiências nutricionais mesmo na soja transgênica (SERRA et al., 2011; JOHAL \& HUBER, 2009). Estas deficiências demonstramse pela redução no acúmulo de nutrientes, alterações na nodulação e, respectivamente, na produção de clorofila e obtenção do N (ZOBIOLE et.al., 2010; ZOBIOLE et al., 2011; SANTOS et al., 2007).

Fatores semelhantes foram observados por ZABLOTOWICZ \& REDDY (2007), que verificaram a redução na produção de raízes e injúrias no vegetal provocadas pela aplicação do glifosato que pode reduzir a fitomassa (SERRA et al., 2011). Isso ocorre pela formação do ácido aminometilfosfônico (AMPA) obtido através da degradação do princípio ativo do herbicida quando entra na rota metabólica do vegetal.

DING et al. (2011) observaram que altas concentrações de AMPA podem reduzir a síntese de clorofila, a fotossíntese e o acúmulo de fitomassa. Outros fatores, como a redução na altura das plantas, produção de vagens e produtividade podem ocorrer, principalmente quando a aplicação ocorre no florescimento (ALBRECHT et al., 2011).

BOTT et al. (2008), comparando as cultivares Conquista e Valiosa RR (similares geneticamente com alteração somente do gene de transgenia), observaram que $\circ$ glifosato tem a capacidade de complexar micronutrientes, o que pode induzir deficiências nutricionais. Teores foliares dos nutrientes $\mathrm{N}, \mathrm{Ca}, \mathrm{Mg}, \mathrm{Fe}$ e $\mathrm{Cu}$ podem ser alterados quando se utiliza o herbicida em doses elevadas (SANTOS et al., 2007).

O tipo de transporte e a disponibilidade dos nutrientes no meio influenciam diretamente sobre a taxa de absorção de nutrientes, que por sua vez afetará o acúmulo destes, pois somente se observam os altos valores de acúmulo de um dado nutriente, quando, antecipadamente, ocorre alta absorção deste (BIANCO et al., 2012). Portanto, fatores como a aplicação do glifosato interferem diretamente no acúmulo dos nutrientes em soja, mesmo nas cultivares transgênicas.

Com isso, objetivou-se avaliar o desempenho de cultivares convencionais e transgênicas de soja, sem aplicação de glifosato, quanto à produção de massa seca, acúmulo de nutrientes e produtividade.

\section{Material e métodos}

O experimento foi conduzido no município de Urutaí (GO), nas coordenadas $48^{\circ} 11^{\prime} 35^{\prime \prime}$ W, $17^{\circ} 28^{\prime} 41^{\prime \prime} \mathrm{S}$ e $800 \mathrm{~m}$ de altitude, entre novembro de 2010 e abril de 2011. Os solos da região são do tipo Latossolo Vermelho (EMBRAPA, 1999). O clima da região, segundo classificação de Köppen, é Aw caracterizado pela existência de duas estações bem definidas: uma chuvosa e quente, outra fria e seca. Ao longo do experimento, foi registrada a precipitação acumulada de $1.171,5 \mathrm{~mm}$, temperatura máxima de $30,91{ }^{\circ} \mathrm{C}$ e mínima de $19,70{ }^{\circ} \mathrm{C}$.

Os tratamentos constaram de onze cultivares de soja, entre convencionais e transgênicas, dispostas em parcelas subdivididas no tempo, com quatro repetições. As convencionais foram a BRSGO 7560 (precoce), BRS Conquista (médio), BRSGO 8360 (médio), BRSGO 7960 (precoce), BRSGO 8660 (médio) e Emgopa 313 (tardio). As transgênicas foram a BRSGO 7760 RR (precoce), BRS 7860 RR (precoce), BRS 8160 RR (médio), BRS Valiosa RR (médio) e Emgopa 313 RR (tardio). As épocas de coleta foram aos $20 ; 40 ; 60 ; 80,100$ dias após o plantio (DAP).

A área experimental foi preparada para o plantio com uma aração e duas gradagens. A adubação ocorreu segundo a necessidade da cultura (SOUSA \& LOBATO, 2004), baseando-se no resultado da análise do solo que indicou os teores: $\mathrm{Ca}=2,7 \mathrm{cmolc} \mathrm{dm}^{-3} ; \mathrm{Mg}=0,4 \mathrm{cmolc} \mathrm{dm}^{-3}$; $\mathrm{H}+\mathrm{Al}=2,6 \mathrm{cmolc} \mathrm{dm}^{-3} ; \mathrm{K}=117,3 \mathrm{~g} \mathrm{dm}^{-3} ; \mathrm{P}=$ $53,0 \mathrm{~g} \mathrm{dm}^{-3}$; Mat. Org. $=12,0 \mathrm{~g} \mathrm{~kg}^{-1} ; \mathrm{S}=5,6 \mathrm{~g} \mathrm{dm}^{-3}$; $\mathrm{Na}=3,0 \mathrm{~g} \mathrm{dm}^{-3} ; \mathrm{Co}=0,03 \mathrm{mg} \mathrm{dm}$; $\mathrm{Zn}=$ $5,6 \mathrm{mg} \mathrm{dm}^{-3} ; \mathrm{B}=0,12 \mathrm{mg} \mathrm{dm}^{-3} ; \mathrm{Cu}=1,8 \mathrm{mg} \mathrm{dm}^{-3}$; $\mathrm{Fe}=47,3 \mathrm{mg} \mathrm{dm}^{-3} ; \mathrm{Mn}=27,0 \mathrm{mg} \mathrm{dm}^{-3} ; \mathrm{Mo}=$ $0,07 \mathrm{mg} \mathrm{dm}^{-3} ;$ CTC $=6,01 \mathrm{mg} \mathrm{dm}^{-3}$; Sat. Bases $=$ $56,79 \mathrm{mg} \mathrm{dm}^{-3}$; pHágua = 5,70; Argila $=350,0 \mathrm{~g} \mathrm{~kg}^{-}$ 1; Areia $=100,0 \mathrm{~g} \mathrm{~kg}^{-1}$; Silte $=550,0 \mathrm{~g} \mathrm{~kg}^{-1}$. Não houve necessidade de calagem e, na adubação, foram aplicados $5,46 \mathrm{~kg}$ de cloreto de potássio e $15,4 \mathrm{~kg}$ de superfosfato simples para suprimento de $40 \mathrm{~kg}$ de $\mathrm{K}_{2} \mathrm{O}$ e $35 \mathrm{~kg}$ de $\mathrm{P}_{2} \mathrm{O}_{5}$, respectivamente, por hectare. 
Para o tratamento de sementes, utilizouse de $0,2 \mathrm{~L}$ de Cruiser $^{\circledR}$ por $100 \mathrm{~kg}$ de semente e $0,3 \mathrm{~L}$ de Vitavax Thiran ${ }^{\circledR}$ por $100 \mathrm{~kg}$ de semente. No dia do plantio, procedeu-se à inoculação com inoculante turfoso contendo as estirpes SEMIA 5019 (Bradyrhizobium elkani) e SEMIA 5079 (Bradyrhizobium japonicum), apresentando o mínimo de $5.10^{9}$ células viáveis por grama de produto. Aplicou-se uma dosagem de 0,4 kg de inoculante para $50 \mathrm{~kg}$ de semente com solução açucarada para a fixação do produto na mesma. Ainda utilizou-se de cloreto de cobalto e molibdato de sódio para suprimento de cobalto e molibdênio, respectivamente.

O manejo de plantas invasoras foi realizado com uma capina manual, aos 30 dias após o plantio. Aos 45 dias após o plantio, aplicou-se 0,75 L.ha $^{-1}$ do produto Fusilade ${ }^{\circledR} 250 \mathrm{EW}$, tendo em vista o controle das mono e dicotiledôneas presentes na área.

A parte aérea de cinco plantas foi lavada em água corrente, submersa em água destilada por um minuto e seca em estufa de circulação forçada de ar a $70{ }^{\circ} \mathrm{C}$ até peso constante. Os teores dos macronutrientes (N, P, K, Ca, Mg e S) e micronutrientes ( $\mathrm{Cu}, \mathrm{Fe}, \mathrm{Mn}$ e $\mathrm{Zn}$ ) foram determinados no tecido vegetal, segundo metodologia de MALAVOLTA et al. (1997). Os acúmulos foram obtidos a partir dos teores de nutrientes e da massa da parte aérea das plantas.

As produtividades, obtidas ao final do ciclo, foram analisadas estatisticamente como delineamento em blocos completos casualizados. Para tanto, coletaram-se todas as plantas em duas linhas de quatro metros por parcela, trilhou-se para separação dos grãos, determinaram-se a massa e a umidade. Os dados foram corrigidos para o padrão de $14 \%$.

Os dados convertidos foram submetidos à análise de variância. Quando significativos em relação às cultivares, realizou-se 0 teste de Tukey, a $5 \%$ de probabilidade. Porém, se a significância encontrada ocorreu entre as cultivares com as épocas, procedeu-se à determinação da regressão dos dados (PIMENTEL-GOMES, 2002).

\section{Resultados e discussão}

Não há diferenças na produção de massa seca entre plantas convencionais e transgênicas, sendo que os índices aumentam progressivamente nas épocas de coleta dos tecidos vegetais. BOTT et al. (2008), comparando a produção de biomassa das cultivares Conquista e Valiosa RR obtiveram que as similares genéticas apresentaram a mesma resposta produtiva. Porém, quando submetida à aplicação de glifosato, a cultivar Valiosa reduz seu crescimento. Fato semelhante ao observado pelos autores ZOBIOLE et al. (2010), ZOBIOLE et al. (2011), DING et al. (2011) e SERRA et al. (2011), que, estudando cultivares transgênicas submetidas a diferentes dosagens de glifosato, devido a sintomas de injúria provocada pela aplicação, obtiveram redução na massa seca da parte aérea das plantas.

Em relação à produtividade, observa-se que há diferenças significativas entre as cultivares. Observando-se a Figura 2, pode-se inferir que a cultivar Valiosa RR apresentou o melhor desempenho produtivo, demonstrando a possibilidade de as cultivares transgênicas produzirem mais do que as convencionais. Comparando-se os resultados obtidos nas Figuras 1 e 2, observase que 0 melhor desempenho vegetativo não necessariamente garante retornos produtivos. A produtividade da cultura também é afetada pela aplicação de glifosato com sua redução progressiva ao aumento da dosagem utilizada (ALBRECHT et al., 2011).

Tabela 1 - Teste de F para fitomassa e produtividade de plantas de soja nas cultivares convencionais e transgênicas, nas épocas de 20; 40; 60; 80 e 100 dias após o plantio. Test $F$ for biomass, productivity of conventional and transgenic soybean cultivars at 20,40,60, 80 and 100 days after planting.

\begin{tabular}{lrrrr}
\hline \multicolumn{1}{c}{ FV } & \multicolumn{2}{c}{ Fitomassa } & \multicolumn{2}{c}{ Produtividade } \\
\hline Cultivares & 1,10 & ${ }^{n s}$ & 3,97 & \\
Bloco & 6,24 & $*$ & 1,53 & ns \\
Época & 252,19 & $*$ & - & \\
Cultivares $x$ & 1,55 & $*$ & - & \\
Época & $*$ & & \\
\hline CV \% & 40,40 & & 24,75 \\
\hline
\end{tabular}

Quanto ao acúmulo de nutrientes, as cultivares não diferiram significativamente entre si, caracterizando que a soja convencional e a transgênica não apresentam diferenças no acúmulo de nutrientes. Resultados semelhantes que retrataram o desenvolvimento das plantas, sendo afetado diretamente pela dosagem e tipo do herbicida aplicado, possuindo as testemunhas o maior acúmulo de nutrientes, foram encontrados por ZOBIOLE et al. (2011). Este fato está diretamente correlacionado com o decréscimo no conteúdo de clorofila, a eficiência fisiológica da planta, a predisposição a doenças e a modificação da microflora do solo, devido ao aumento da dosagem e à utilização do herbicida (JOHAL \& HUBER, 2009). 


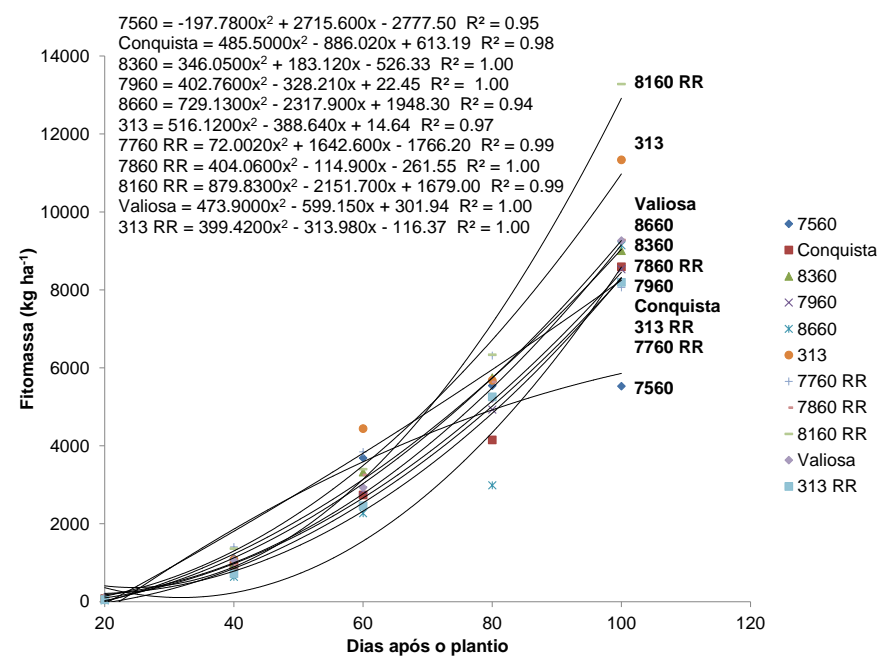

Figura 1 - Fitomassa acumulada das cultivares convencionais e transgênicas, nas épocas de 20; 40; 60; 80 e 100 dias após o plantio. Urutaí-GO, 2011. Accumulated biomass of conventional and transgenic soybean cultivars at 20, 40, 60, 80 and 100 days after planting. Urutaí-GO, 2011.

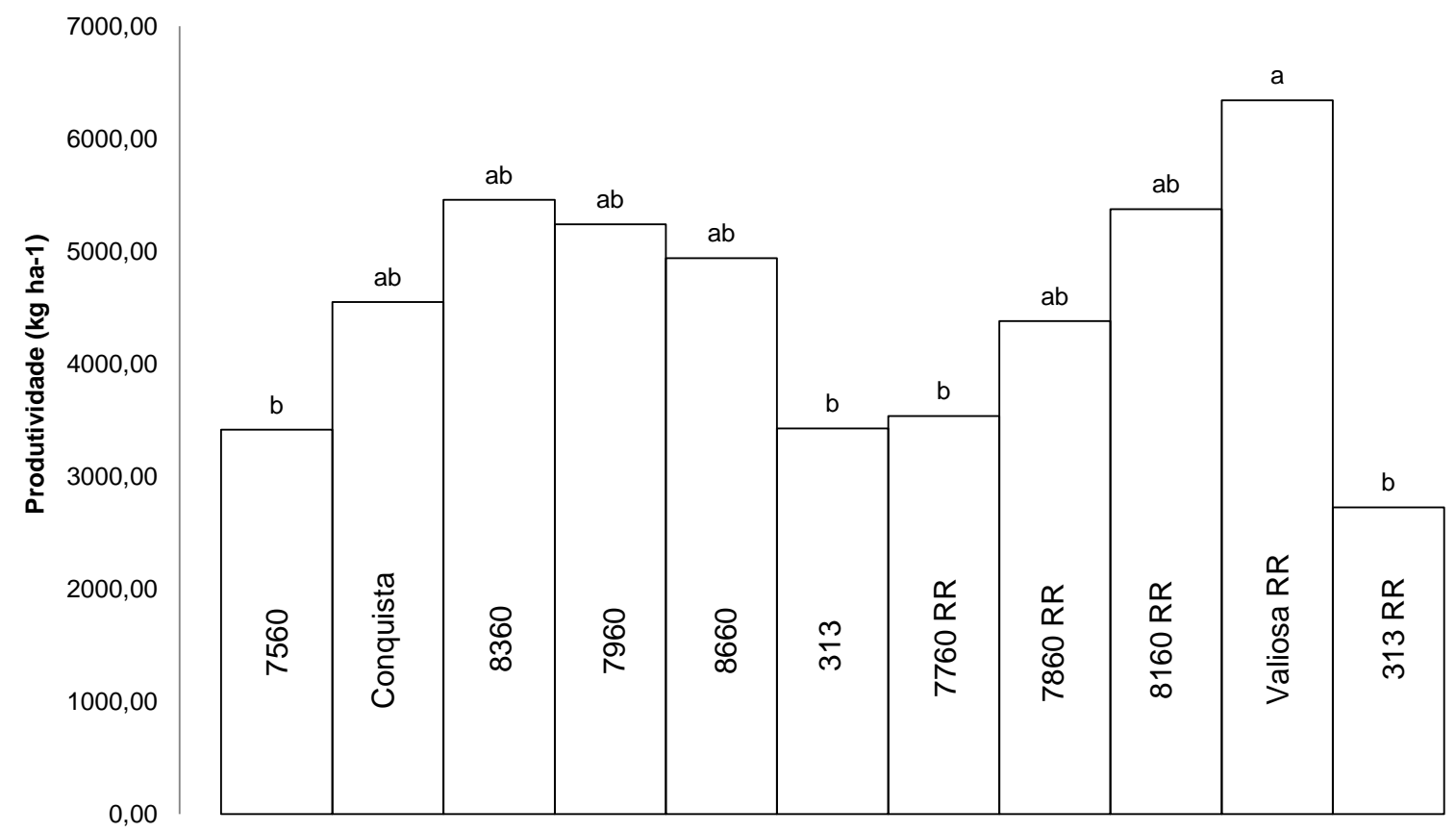

Figura 2 - Produtividade obtida por cultivar de soja convencional e transgênica. Urutaí-GO, 2011. Productivity of conventional and transgenic soybean cultivars. Urutaí-GO, 2011.

Quanto ao acúmulo de nutrientes, as cultivares não diferiram significativamente entre $\mathrm{si}$, caracterizando que a soja convencional e a transgênica não apresentam diferenças no acúmulo de nutrientes. Resultados semelhantes que retrataram o desenvolvimento das plantas, sendo afetado diretamente pela dosagem e tipo do herbicida aplicado, possuindo as testemunhas o maior acúmulo de nutrientes, foram encontrados por ZOBIOLE et al. (2011). Este fato está diretamente correlacionado com o decréscimo no conteúdo de clorofila, a eficiência fisiológica da planta, a predisposição a doenças e a modifica- ção da microflora do solo, devido ao aumento da dosagem e à utilização do herbicida (JOHAL \& HUBER, 2009).

O glifosato interfere de forma negativa na eficiência de absorção e, consequentemente, de acúmulo de nutrientes, mesmo para as cultivares RR (SERRA et al., 2011; CAVALIERI et al., 2012). SANTOS et al. (2007) já ressaltavam que não se deve aplicar a formulação Roundup Ready em doses elevadas, visto que o herbicida é capaz de alterar o teor de nutrientes nas folhas da cultura. Além dos teores de nutrientes, ALBRECHT et al. (2011) constataram que a utili- 
zação do glifosato interfere inclusive no conteúdo de proteína dos grãos.

Observam-se diferenças para $\mathrm{Ca}$ e $\mathrm{Mn}$ devido à baixa produção de fitomassa da cultivar 7560, que apresenta o menor acúmulo, como pode ser observado através do teste de Tukey ( $p>0,05)$, na Tabela 2. As cultivares apresentam desenvolvimento distinto, o que foi comprovado pela interação significativa entre estas e a época de coleta. Os acúmulos para os macronutrientes $(\mathrm{N}, \mathrm{P}, \mathrm{Ca}$ e $\mathrm{Mg}$ ) e micronutrientes ( $\mathrm{Cu}, \mathrm{Fe}, \mathrm{Mn}$ e $\mathrm{Zn}$ ) encontram-se nas Figuras 3 e 4 . As plantas apresentam acúmulos semelhantes somente para os nutrientes $\mathrm{K}$ e S. Quanto ao K, este comportamento explica-se pela alta concentração do nutriente no solo e pela sua alta disponibilidade.

Tabela 2 - Acúmulo dos macronutrientes (N, P, K, Ca, Mg e S) em kg.ha-1 e micronutrientes (Cu, $\mathrm{Fe}$, Mn e Zn) em g.ha ${ }^{-1}$, em plantas de soja, nas cultivares, nas épocas de 20; 40;60; 80 e 100 dias após o plantio. Macronutrients accumulation (N, $\mathrm{P}, \mathrm{K}, \mathrm{Ca}, \mathrm{Mg}$ and $\mathrm{S}$ ) in $\mathrm{kg}^{-\mathrm{ha}^{-1}}$ and micronutrients $(\mathrm{Cu}, \mathrm{Fe}$, $\mathrm{Mn}$ and $\mathrm{Zn}$ ) in g.ha $^{-1}$ of conventional and transgenic soybean cultivars at 20, 40,60, 80 and 100 days after planting.

\begin{tabular}{|c|c|c|c|c|c|c|c|c|c|c|c|c|c|c|c|c|c|c|c|c|}
\hline \multirow{2}{*}{$\mathrm{FV}$} & \multicolumn{2}{|l|}{$\mathrm{N}$} & \multicolumn{2}{|l|}{$\mathrm{P}$} & \multicolumn{2}{|l|}{$\mathrm{K}$} & \multicolumn{2}{|l|}{$\mathrm{Ca}$} & \multicolumn{2}{|l|}{$\mathrm{Mg}$} & \multicolumn{2}{|l|}{$\mathrm{S}$} & \multicolumn{2}{|l|}{$\mathrm{Cu}$} & \multicolumn{2}{|l|}{$\mathrm{Fe}$} & \multicolumn{2}{|l|}{$\mathrm{Mn}$} & \multicolumn{2}{|l|}{$\mathrm{Zn}$} \\
\hline & \multicolumn{12}{|c|}{ - } & \multicolumn{8}{|c|}{ - } \\
\hline $\begin{array}{c}\text { Cultivares } \\
\text { (C) }\end{array}$ & 14,04 & ns & 16,35 & ns & 0,75 & ns & 20,06 & * & 10,43 & ns & 0,87 & ns & 0,66 & ns & 17,60 & ns & 28,02 & * & 17,71 & ns \\
\hline Bloco & 57,21 & ** & 63,67 & ** & 63,60 & ** & 51,61 & $* *$ & 57,36 & $* *$ & 66,15 & $* *$ & 74,31 & ** & 63,89 & ** & 42,56 & * & 55,03 & ** \\
\hline $\begin{array}{c}\text { Época } \\
\text { (E) }\end{array}$ & 273,57 & $* *$ & 284,96 & $* *$ & 231,69 & $* *$ & 259,30 & $* *$ & 239,91 & $\star *$ & 273,07 & $* *$ & 166,72 & $* *$ & 240,34 & $\star *$ & 237,22 & $\star \star$ & 246,46 & ** \\
\hline$C \times E$ & 19,53 & ** & 17,07 & * & 14,38 & ns & 39,56 & ** & 2,33 & ** & 11,53 & ns & 2,60 & ** & 29,74 & ** & 46,41 & ** & 29,92 & ** \\
\hline CV \% & 40,30 & & 40,32 & & 38,25 & & 42,67 & & 41,41 & & 42,08 & & 35,78 & & 38,94 & & 40,53 & & 39,31 & \\
\hline \multicolumn{21}{|c|}{ Teste de Tukey $(p>0,05)$} \\
\hline 7560 & 79,38 & $a$ & 11,49 & a & 65,27 & $a$ & 29,06 & $b$ & 12,53 & a & 6,00 & a & 9,33 & a & 705,24 & a & 88,52 & $b$ & 73,47 & a \\
\hline Conquista & 78,91 & a & 9,98 & a & 66,30 & a & 51,50 & $a b$ & 16,70 & a & 5,25 & a & 10,06 & a & 796,42 & a & 145,83 & $a b$ & 86,78 & $a$ \\
\hline 8360 & 105,56 & $a$ & 11,76 & a & 82,16 & $a$ & 47,67 & $a b$ & 17,35 & a & 5,76 & a & 11,01 & $\mathrm{a}$ & 1094,19 & $a$ & 125,41 & $a b$ & 90,80 & a \\
\hline 7960 & 95,23 & a & 11,21 & a & 76,53 & a & 38,99 & $a b$ & 13,30 & $a$ & 5,35 & a & 10,31 & $a$ & 744,99 & $\mathrm{a}$ & 119,31 & $a b$ & 76,44 & a \\
\hline 8660 & 70,85 & a & 8,96 & a & 68,14 & $\mathrm{a}$ & 43,70 & $a b$ & 12,91 & a & 5,14 & $\mathrm{a}$ & 8,06 & a & 960,15 & $\mathrm{a}$ & 149,45 & $a b$ & 72,16 & a \\
\hline 313 & 89,28 & $\mathrm{a}$ & 12,16 & a & 92,39 & a & 65,21 & a & 14,64 & $\mathrm{a}$ & 6,33 & a & 11,59 & $\mathrm{a}$ & 1267,62 & $a$ & 166,33 & $a b$ & 69,44 & a \\
\hline $7760 \mathrm{RR}$ & 98,34 & $a$ & 12,93 & a & 84,63 & $a$ & 46,74 & $a b$ & 16,65 & a & 6,21 & a & 10,43 & $a$ & 743,95 & $\mathrm{a}$ & 125,59 & $a b$ & 75,73 & $a$ \\
\hline $7860 \mathrm{RR}$ & 95,95 & $a$ & 12,41 & a & 75,48 & a & 47,29 & $a b$ & 17,23 & a & 6,36 & a & 8,48 & a & 885,67 & $a$ & 150,26 & $a b$ & 86,87 & a \\
\hline 8160 RR & 125,01 & $\mathrm{a}$ & 14,96 & a & 95,26 & a & 55,35 & $a b$ & 19,82 & $a$ & 7,56 & a & 11,67 & $\mathrm{a}$ & 1087,93 & $\mathrm{a}$ & 221,48 & $\mathrm{a}$ & 125,09 & $a$ \\
\hline Valiosa & 94,72 & $\mathrm{a}$ & 10,82 & a & 75,73 & $a$ & 58,57 & $a b$ & 17,74 & $a$ & 5,49 & $\mathrm{a}$ & 9,03 & $\mathrm{a}$ & 1046,39 & $a$ & 159,64 & $a b$ & 78,24 & a \\
\hline $313 \mathrm{RR}$ & 77,51 & a & 7,59 & a & 72,52 & $a$ & 40,95 & $a b$ & 13,68 & $a$ & 4,68 & a & 9,39 & $\mathrm{a}$ & 855,96 & $a$ & 104,02 & $b$ & 70,88 & a \\
\hline
\end{tabular}


(a)

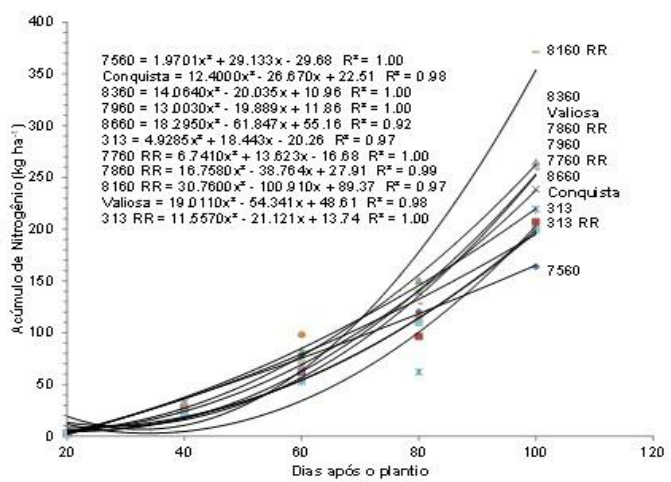

(c)

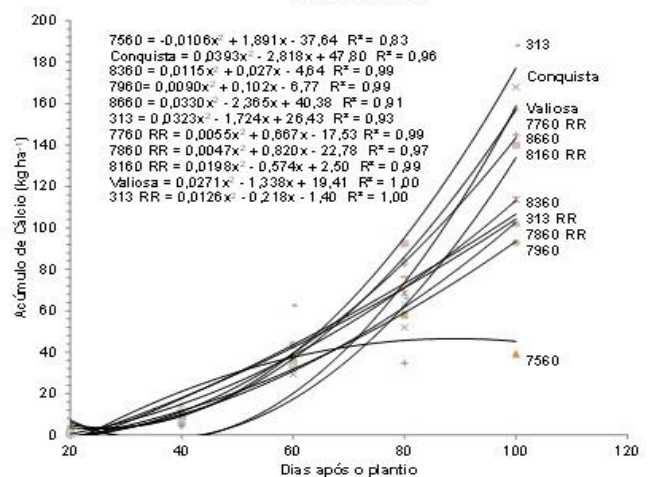

(b)

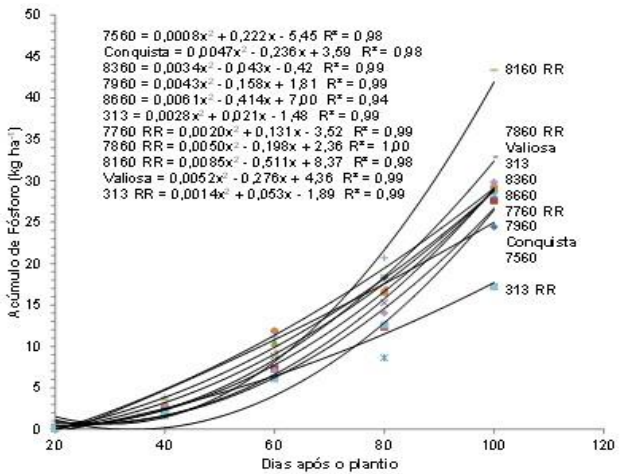

(d)

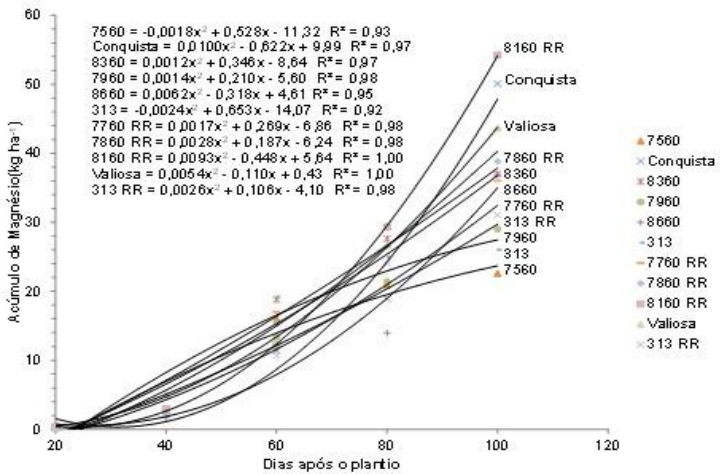

Figura 3 - Acúmulo dos nutrientes $\mathrm{N}(\mathrm{a}), \mathrm{P}$ (b), $\mathrm{Ca}$ (c) e $\mathrm{Mg}$ (d) em plantas de soja convencional e transgênica, nas épocas de coleta de 20; 40;60; 80 e 100 dias após o plantio, Urutaí-GO, 2011. N (a), $P$ (b), Ca (c) and $M g$ (d) accumulation in conventional and transgenic soybean cultivars at 20, 40, 60, 80 and 100 days after planting. Urutaí-GO, 2011.
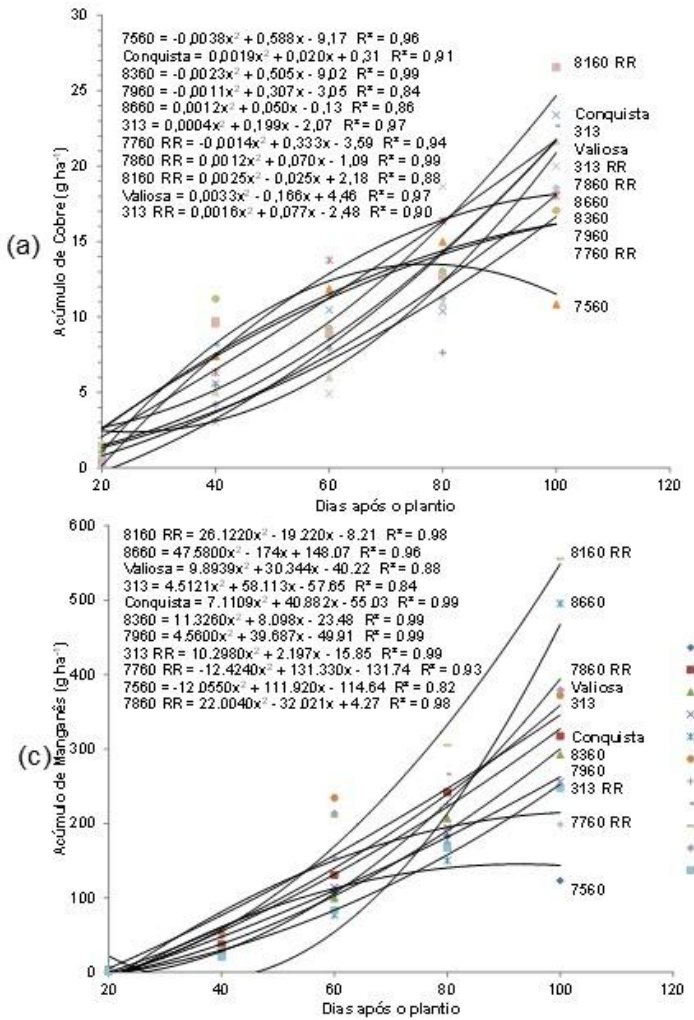

(b)
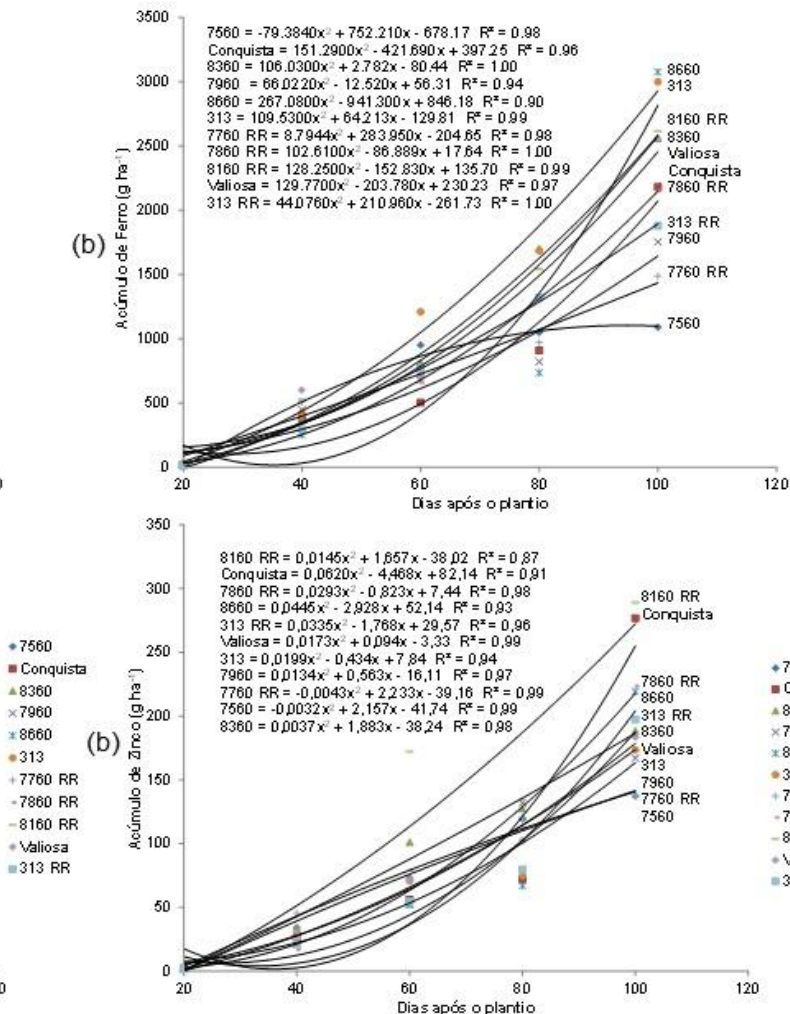

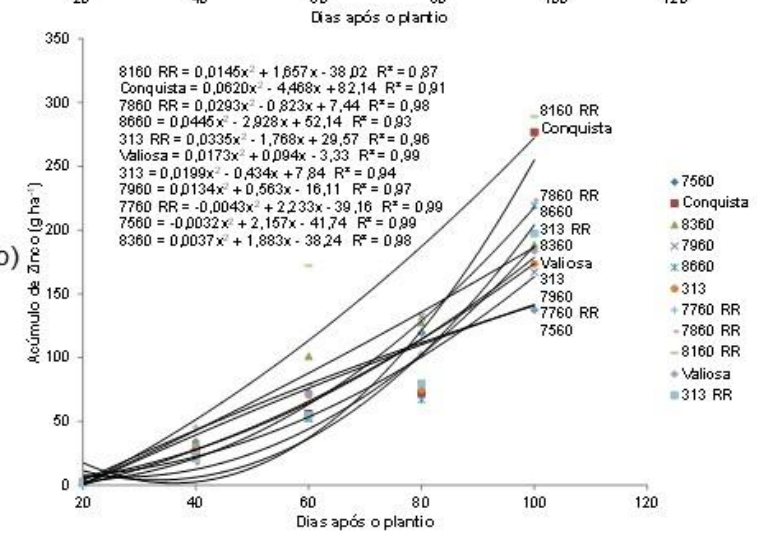

Figura 4 - Acúmulo dos nutrientes $\mathrm{Cu}(\mathrm{a}), \mathrm{Fe}$ (b), Mn (c) e Zn (d) em plantas de soja convencional e transgênica, nas épocas de coleta de 20;40;60;80 e 100 dias após o plantio, Urutaí-GO, 2011. Cu (a), Fe (b), Mn (c) and $\mathrm{Zn}$ (d) accumulation accumulation in conventional and transgenic soybean cultivars at 20, 40, 60, 80 and 100 days after planting.. Urutaí-GO, 2011. 


\section{Conclusões}

As cultivares transgênicas, quando cultivadas sem aplicação de glifosato, são eficientes quanto à produção de fitomassa, produtividade e acúmulo de nutrientes, estatisticamente semeIhantes às convencionais.

Para tanto, a cultivar mais produtiva foi a Valiosa RR, em detrimento das cultivares com menor rendimento, tais como: 7560; 313; 7760 RR e 313RR. Houve também interação entre as cultivares e as épocas de coleta para o acúmulo de nutrientes.

\section{Referências}

ALBRECHT, L. P.; BARBOSA, A. P.; SILVA, A. F. M.; MENDES, M. A.; MARASCHI-SILVA, L. M.; ALBRECHT, A. J. P. Desempenho da soja roundup ready sob aplicação de glyphosate em diferentes estádios. Planta Daninha, Viçosa, MG, v.29, n.3, p.585-590, 2011.

BIANCO, S.; CARVALHO, L. B.; BIANCO, M. S.; PITELLI, R. A. Acúmulo de massa seca e macronutrientes por plantas de Glycine max e Solanum americanum. Planta Daninha, Viçosa, MG, v.30, n.1, p.87-95, 2012.

BOTT, S.; TESFAMARIAM, T.; CANDAN, H.; CAKMAK, I.; RÖMHELD, V.; NEUMANN, G. Glyphosate-induced impairment of plant growth and micronutriente status in glyphosate-resistant soybean (Glycine max L.). Plant Soil, The Hague, v.312, n.1-2, p.185-194, 2008.

CAVALIERI, S. D.; VELINI, E. D.; SILVA, F. M. L.; SÃO JOSÉ, A. R.; ANDRADE, G. J. M. Acúmulo de nutrientes e matéria seca na parte aérea de dois cultivares de soja RR sob efeito de formulações de glyphosate. Planta Daninha, Viçosa, MG, v.30, n.2, p.349-358, 2012.

CONAB - Companhia Nacional de Abastecimento. Acompanhamento da safra brasileira: grãos, nono levantamento, julho 2013. Brasília: Conab, 2013.

DING, W.; REDDY, K. N.; ZABLOTOWICZ, R. M.; BELLALOUI, N.; BRUNS, H. A. Physiological responses of glyphosate-resistant and glyphosatesensitive soybean to aminomethylphosphonic acid, a metabolite of glyphosate. Chemosphere, v.83, n.4, p.593-598, 2011.

EMBRAPA. Centro Nacional de Pesquisa de Solos. Sistema brasileiro de classificação dos solos. Rio de Janeiro: Embrapa-SPI/EmbrapaCNPS, 1999.

GUIVANT, J. S. Transgênicos e percepção pública da ciência no Brasil. Ambiente \& Sociedade, Campinas, v.9, n.1, p.81-103, 2006.

JOHAL, G. S.; HUBER, D. M. Glyphosate effects on diseases of plants. European Journal of
Agronomy, Amsterdam, v.31, n.3, p.144-152, 2009.

MALAVOLTA, E.; VITTI, G. C.; OLIVEIRA, S. A. de. Avaliação do estado nutricional das plantas: princípios e aplicações. Piracicaba: POTAFOS, 1997.

MALTY, J. S.; SIQUEIRA, J. O; MOREIRA, F. M. $S$. Efeitos do glifosato sobre microrganismos simbiotróficos de soja, em meio de cultura e casa de vegetação. Pesquisa Agropecuária Brasileira, v.41, n.2, p.285-291, 2006.

PIMENTEL-GOMES, F. Estatística aplicada a experimentos agronômicos e florestais: exposição com exemplos e orientações para uso de aplicativos. Piracicaba: FEALQ, 2002.

SANTOS, J. B.; FERREIRA, E. A.; REIS, M. R.; SILVA, A. A.; FIALHO, C. M. T.; FREITAS, M. A. M. Avaliação de formulações de glyphosate sobre soja roudup ready. Planta Daninha, Viçosa, MG, v.25, n.1, p.165-171, 2007.

SERRA, A. P.; MARCHETTI, M. E.; CANDIDO, A. C. S.; DIAS, A. C. R.; CHRISTOFFOLETI, P. J. Influência do glifosato na eficiência nutricional do nitrogênio, manganês, ferro, cobre e zinco em soja resistente ao glifosato. Ciência Rural, Santa Maria, v.41, n.1, p.77-84, 2011

SOUSA, D. M. G.; LOBATO, E. Cerrado: correção do solo e adubação. 2.ed. Brasília: Embrapa Informação Tecnológica, 2004. 416p.

SOUZA, R. A.; HUNGRIA, M.; FRANCHINI, J. C.; CHUEIRE, L. M. O.; BARCELLOS, F. G.; CAMPO, R. J. Avaliação qualitativa e quantitativa da microbiota do solo e da fixação biológica do nitrogênio pela soja. . Pesquisa Agropecuária Brasileira, Brasília, v.43, n.1, p.71-82, 2008.

ZABLOTOWICZ, R. M.; REDDY, K. N. Nitrogenase activity, nitrogen content, and yield responses to glyphosate in glyphosate-resistant soybean. Crop Protection, Guildford, v.26, n.3, p.370-376, 2007.

ZOBIOLE, L. H. S.; OLIVEIRA, R. S.; KREMER, R. J.; CONSTANTIN, J.; YAMADA, T.; CASTRO, C.; OLIVEIRA, F. A.; OLIVEIRA Jr., A. Effect of glyphosate on symbiotic N2 fixation and nickel concentration in glyphosate-resistant soybeans. Applied Soil Ecology, Amsterdam, v.44, n.1, p.176-180, 2010.

ZOBIOLE, L. H. S.; KREMER, R. J.; OLIVEIRA Jr., R. S.; CONSTANTIN, J. Glyphosate affects chlorophyll, nodulation and nutrient accumulation of "second generation" glyphosate-resistant soybean (Glycine max $\quad$ L.). Pesticide Biochemistry and Physiology, San Diego, v.99, n.1, p.53-60, 2011. 